\title{
Cadmium Sulfide Photocatalysed Reduction of Malachite Green by Ascorbic Acid and EDTA as Reductants
}

\author{
Shilpa Kothari, Anil Kumar, Ritu Vyas, Rakshit Ameta and Pinki B. Punjabi* \\ Photochemistry and Solar Energy Laboratory, Department of Chemistry, College of Science, \\ Mohanlal Sukhadia University, Udaipur - 313002 [Raj.], India
}

\begin{abstract}
Foi efetuada a fotoredução do verde de malaquita na presença de CdS como fotocatalizador e ácido ascorbico/EDTA como redutores. Foram estudados os efeitos de diferentes parâmetros como $\mathrm{pH}$, concentração de verde de malaquita, redutores, quantidade de semicondutor e intensidade de luz, na velocidade da reação fotocatalítica. Levando em conta os dados obtidos propomos um de mecanismo.para a fotoredução do verde de malaquita.
\end{abstract}

The photoreduction of malachite green in presence of $\mathrm{CdS}$ as photocatalyst and ascorbic acid/ EDTA as reductants has been carried out. The effect of different parameters like $\mathrm{pH}$, concentration of malachite green, reductants, amount of semiconductor and light intensity on the rate of photocatalytic reaction has been studied. On the basis of observed data, a tentative mechanism for the photoreduction of malachite green has been proposed.

Keywords: photocatalytic reduction, cadmium sulfide, malachite green, ascorbic acid, EDTA

\section{Introduction}

Water is one of the fundamental requirements of life and any undesired addition of chemical substances leads to its contamination and makes it unfit for human utility. Generally, various dyes found in industrial effluents, ultimately, enter the aquatic ecosystem and can create environmental hazards. These effluents have very adverse and sometimes irreversible effects on other animals and plants as well. The main purpose of waste water treatment is the removal of these toxic substances and color, and to make the water usable for industrial and domestic use. There are various methods like adsorption, osmosis, flocculation etc, which have been used traditionally to remove these dyes from the water bodies, but these methods suffer from some drawbacks. In recent years, Advanced Oxidation Processes (AOP's) like photocatalysis, photo-Fenton reaction, ozonation, sonolysis etc, have emerged as successful techniques in combating against the problem of environmental pollution. Research work and applications based on AOP's in treatment of water has increased considerably during last twenty five years. The photocatalytic bleaching was found to be the most promising and efficient process in controlling

*e-mail: pb_punjabi@yahoo.com the environmental pollution, waste water treatment etc, in which semiconductor particles act as photocatalysts or short-circuited microelectrodes on excitation. On excitation, semiconductor generates electron-hole pair which may be used either for reduction or oxidation of the dye.

Exhaustive researches in the field of photocatalysis have shown various fascinating applications of photocatalytic reactions based on the use of semiconductors. ${ }^{1,2}$ The photocatalytic degradation of methylene blue, rhodamine-B and methyl orange in presence of CdS as photocatalyst has been reported. ${ }^{3,4}$ Kominami et al. ${ }^{5}$ investigated photodegradation, decolourisation and mineralization of malachite green in aqueous suspension of $\mathrm{TiO}_{2}$ nanoparticles under aerated conditions. Semiconductor iron (III) oxide has been used for the photocatalytic bleaching of some dyes like malachite green, methylene blue and crystal violet. ${ }^{6}$ Photodegradation of dye pollutants on silica gel supported $\mathrm{TiO}_{2}$ particles under visible light has been studied by Chen et $a l .{ }^{7}$ Photocatalytic degradation of textile azo dye, (Sirius Gelb) on $\mathrm{TiO}_{2}$ or $\mathrm{Ag}-\mathrm{TiO}_{2}$ particles in the absence and presence of UV irradiation has been reported by Ozkan et al. ${ }^{8}$ The photobleaching of crystal violet over $\mathrm{ZnO}$ was studied by Rao et al. ${ }^{9}$ Sharma et al. ${ }^{10,11}$ reported photocatalytic degradation of xylidine ponceau and orange-G. Photoreduction of fluorescent dye 
2',7'-dichlorofluorescein was reported by Marchesi et al. ${ }^{12}$ Punjabi et al. ${ }^{13}$ studied the photoreduction of congo red by ascorbic acid and EDTA as reductants and cadmium sulfide as photocatalyst.

In spite of many uses, the dyes are toxic and carcinogenic. Environmental contamination by these toxic chemicals has emerged as a serious global problem. Colored solutions containing dyes from industrial effluents of textile, dyeing and printing industries may cause skin cancer due to photosensitization and photodynamic damage. On the other hand, bleached dye solution is less toxic. Secondly, colored water containing dyes is of almost no use, but if this colored solution is bleached to give colorless water, then it may be used for washing, cooling, irrigation and cleaning purposes.

The photocatalytic bleaching of dyes provides a new method for the treatment of wastewater from dyeing and printing industries. The only problem associated with this treatment is the slow rate of degradation of dyes. It is therefore, important to find some suitable modifications to make this technique more effective. The photoreduction of dyes on CdS semiconductor in the presence of ascorbic acid and EDTA as reductants provide a low cost method to solve this problem. Therefore, the present work has been undertaken.

\section{Experimental}

$0.3640 \mathrm{~g}$ of malachite green was dissolved in $100.0 \mathrm{~mL}$ of doubly distilled water so that the concentration of dye solution was $1.0 \times 10^{-3} \mathrm{~mol} \mathrm{~L}^{-1}$. It was used as a stock solution. This solution was used after further dilution. The absorbance of this dye solution was determined with the help of a spectrophotometer $\left(\lambda_{\text {max }} 620 \mathrm{~nm}\right)$. The solution was divided into four parts: the first beaker containing only dye solution was kept in dark; the second beaker containing only dye solution was kept in sunlight; $0.20 \mathrm{~g}$ of semiconductor cadmium sulfide was added to the third beaker containing dye solution and reductant (ascorbic acid/ EDTA) and it was kept in dark; $0.20 \mathrm{~g}$ of semiconductor cadmium sulfide was added to the fourth beaker containing dye solution and reductant (ascorbic acid/EDTA) and was exposed to sunlight.

These beakers were kept for $4 \mathrm{~h}$ and then the absorbance of solution in each beaker was measured. It was observed that the solutions in the first three beakers had the almost same initial absorbance while the solution in the fourth beaker had a decrease in its initial value of absorbance. Thus, by performing blank experiment it was confirmed that the reaction between malachite green and semiconductor powder is neither thermal nor photochemical but it is a photocatalytic reaction. The reaction was carried out in the presence of reductants ascorbic acid (Set-I) and EDTA (SetII). A $200 \mathrm{~W}$ tungsten lamp (Philips) was used as a source of irradiation. A water filter was used to cut off thermal radiations. The progress of the reaction was monitored spectrophotometrically by taking absorbance of the reaction mixture at different time intervals.

\section{Results and Discussion}

An aliquot of $4.0 \mathrm{~mL}$ was taken out from the reaction mixture and the change in absorbance was observed $\left(\lambda_{\max } 620 \mathrm{~nm}\right)$ with time of exposure.

The plot of $\log$ A vs. time was linear in two stages. Hence, this reaction follows pseudo-first order kinetics. The rate constants $\mathrm{k}_{1}$ and $\mathrm{k}_{2}$ of the reaction were determined by the expression.

$\mathrm{k}=2.303 \times$ slope

The first stage is a fast step, which is followed by a slower step $\left(k_{1}>k_{2}\right)$. This may be due to the fact that initially the dye bleaching is faster as hole scavengers (ascorbic acid/ EDTA) will facilitate the removal of $\mathrm{h}^{+}$, thus providing more electrons for reduction of the dye but as the reaction proceeds the concentration of hole scavengers will also decrease resulting in a reduction in the rate of the reaction.

It was observed that the absorbance of malachite green solution in presence of semiconductor was lower as compared to sample without semiconductor at the same time intervals. It means that the rate of this photocatalytic degradation is favorably affected by a semiconductor in case of malachite green. The results of typical run are reported in Table 1 and graphically presented in Figure 1.

\section{Effect of $p H$}

The $\mathrm{pH}$ of the solution is likely to affect the bleaching of the dye. The effect of $\mathrm{pH}$ on the rate of bleaching of dye solution was investigated in the $\mathrm{pH}$ range 5.5-9.0. It was observed that the color of malachite green bleaches in strongly acidic medium. Therefore study was carried out starting from weakly acidic to alkaline medium. The results are reported in Figure 2.

It was observed that the rate of photocatalytic bleaching of dye was increased with increase in the $\mathrm{pH}$ of the solution. This kind of behaviour of malachite green suggests that it does not bleach so easily in acidic range, where it exists in the form of a protonated species. The point of zero change $\left(\mathrm{P}_{\mathrm{z}} \mathrm{C}\right)$ for $\mathrm{CdS}$ was measured as 7.0 under experimental conditions. The optimum rate of degradation for this 
Table 1. Typical run

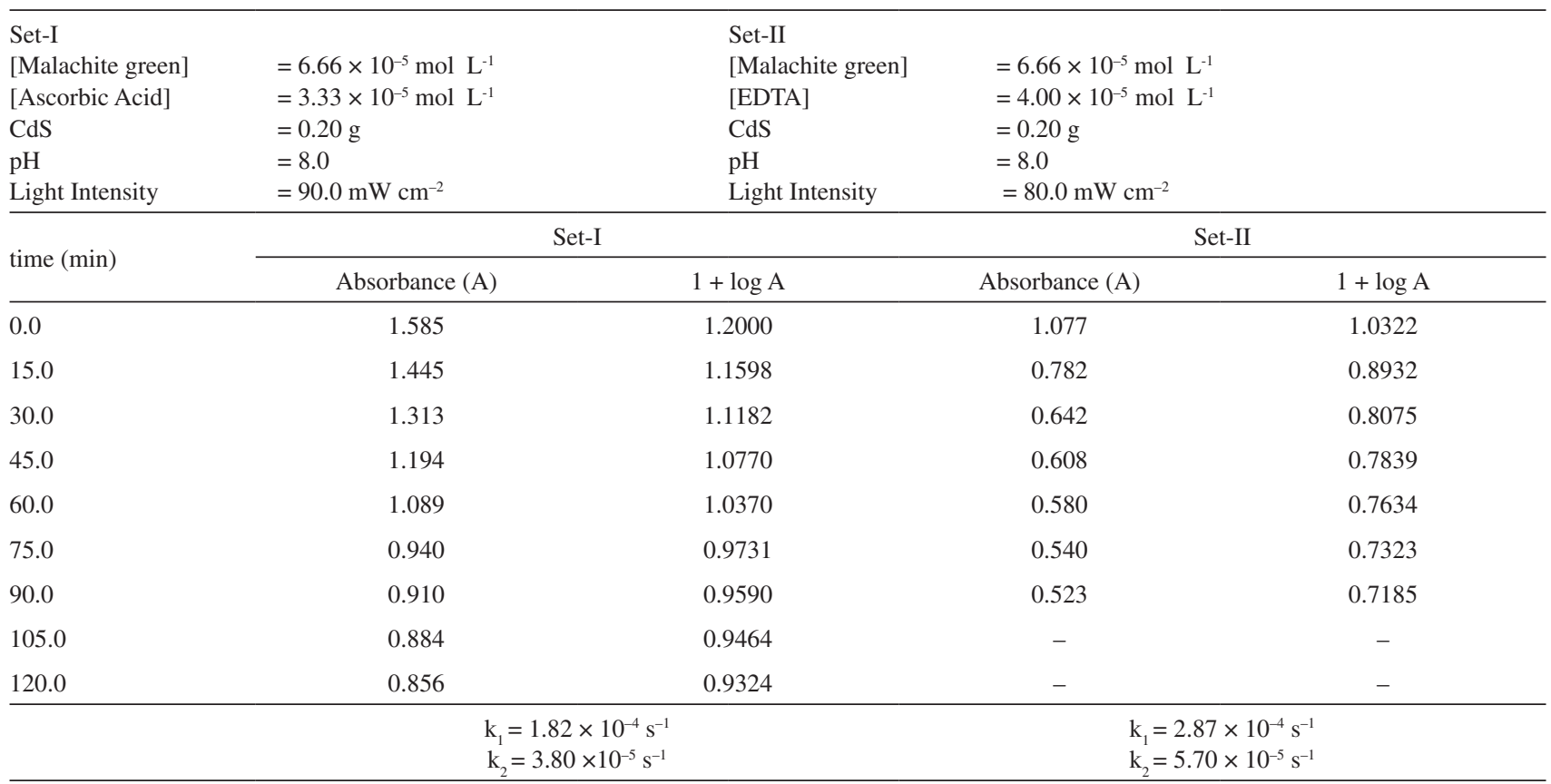

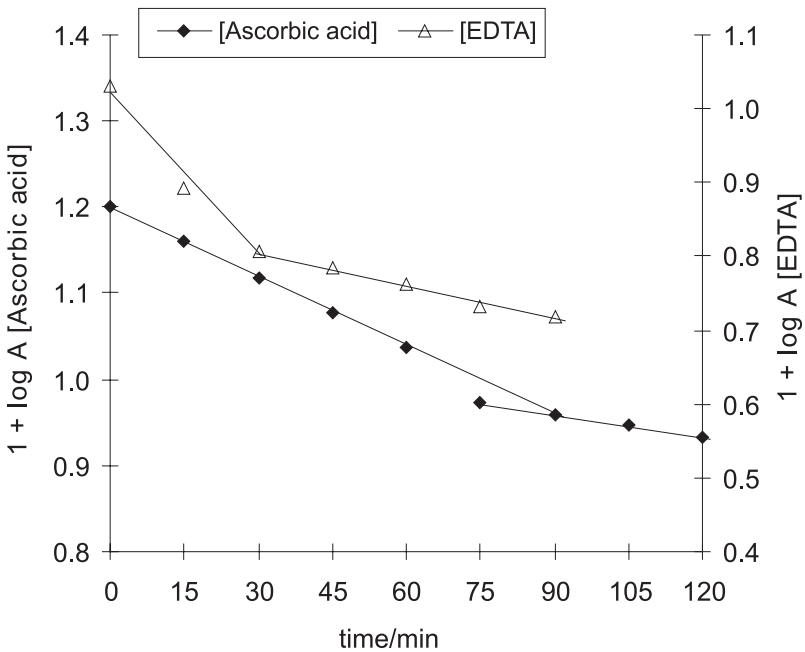

Figure 1. Typical run of photocatalytic reduction of malachite green. Set-I: $[$ Malachite green $]=6.66 \times 10^{-5} \mathrm{~mol} \mathrm{~L}^{-1}$, [Ascorbic Acid] $=3.33 \times 10^{-5}$ mol L ${ }^{-1}, \mathrm{CdS}=0.20 \mathrm{~g}, \mathrm{pH} 8.0$, Light Intensity $=90.0 \mathrm{~mW} \mathrm{~cm}{ }^{-2}$; Set-II: $[$ Malachite green $]=6.66 \times 10^{-5} \mathrm{~mol} \mathrm{~L}^{-1},[$ EDTA $]=4.00 \times 10^{-5} \mathrm{~mol} \mathrm{~L}^{-1}$, $\mathrm{CdS}=0.20 \mathrm{~g}, \mathrm{pH} 8.0$, Light Intensity $=80.0 \mathrm{mWcm}^{-2}$.

reaction was obtained at $\mathrm{pH}$ 8.0, i.e., higher $\mathrm{pH}$ than $\mathrm{P}_{\mathrm{z}} \mathrm{C}$ of CdS. Now, as the $\mathrm{pH}$ was increased above 7.0, the concentration of hydroxyl ions increases. These hydroxyl ions remain adsorbed on the surface of the semiconductor $\mathrm{CdS}$; thus, making the surface negatively charged. The electrostatic attraction between the cationic form of the dye malachite green and negatively charged semiconductor surface will favour the approach of the dye molecules towards the surface of the semiconductor. This results in

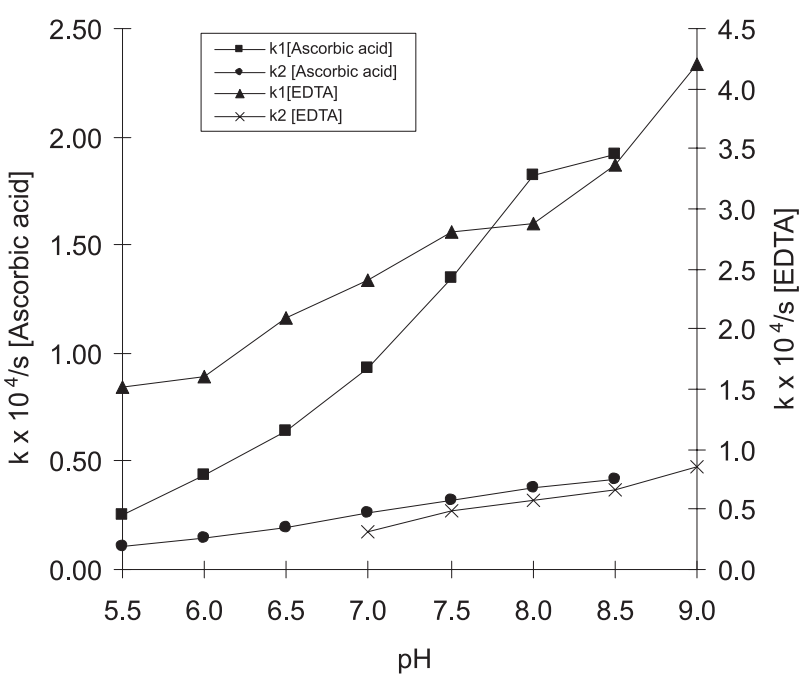

Figure 2. Effect of $\mathrm{pH}$ on photocatalytic reduction of malachite green: Set-I: [Malachite green] $=6.66 \times 10^{-5} \mathrm{~mol} \mathrm{~L}^{-1}$, [Ascorbic Acid] $=$ $3.33 \times 10^{-5} \mathrm{~mol} \mathrm{~L}^{-1}, \mathrm{CdS}=0.20 \mathrm{~g}$, Light Intensity $=90.0 \mathrm{~mW} \mathrm{~cm}^{-2} ;$ Set-II: $[$ Malachite green $]=6.66 \times 10^{-5} \mathrm{~mol} \mathrm{~L}^{-1},[$ EDTA $]=4.00 \times 10^{-5} \mathrm{~mol} \mathrm{~L}^{-1}$, $\mathrm{CdS}=0.20 \mathrm{~g}$, Light Intensity $=80.0 \mathrm{~mW} \mathrm{~cm}^{-2}$.

an increase in the rate of bleaching of malachite green. For EDTA, the two stage behaviour of the $\log$ A $v s$. time below 7.0 changes to a single stage.

\section{Effect of malachite green concentration}

Effect of change of dye concentration was also studied by taking different concentrations of malachite green. The results are reported in Figure 3. 


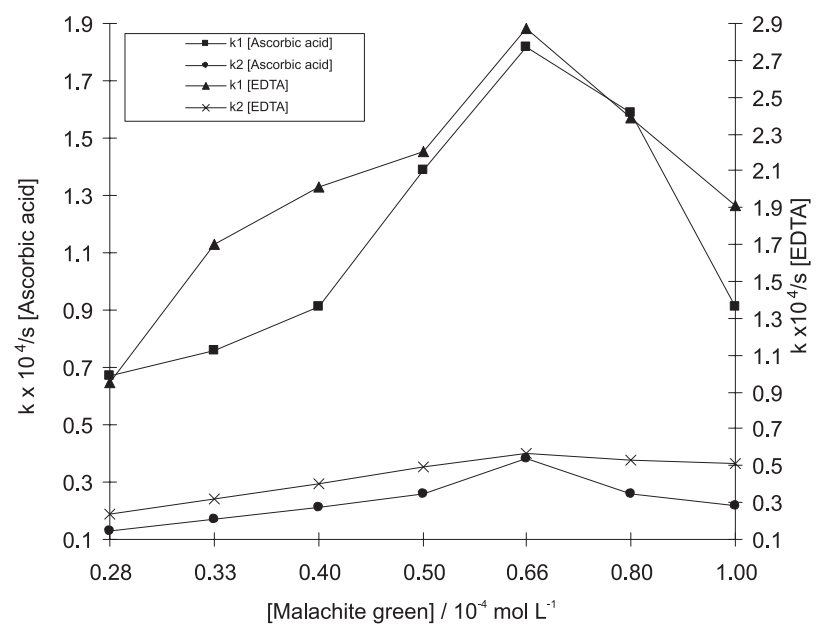

Figure 3. Effect of concentration of malachite green on photocatalytic reduction. Set-I: [Ascorbic Acid] $=3.33 \times 10^{-5} \mathrm{~mol} \mathrm{~L}^{-1}, \mathrm{CdS}=0.20 \mathrm{~g}, \mathrm{pH} 8.0$, Light Intensity $=90.0 \mathrm{~mW} \mathrm{~cm}{ }^{-2}$; Set-II: $\left[\right.$ EDTA] $=4.00 \times 10^{-5} \mathrm{~mol} \mathrm{~L}^{-1}$, $\mathrm{CdS}=0.20 \mathrm{~g}, \mathrm{pH} 8.0$, Light Intensity $=80.0 \mathrm{~mW} \mathrm{~cm}^{-2}$.

It has been observed that the rate of photocatalytic bleaching increases up to $6.66 \times 10^{-5} \mathrm{~mol} \mathrm{~L}^{-1}$ for both Set-I and Set-II with an increase in the concentration of the dye. A further increase in the concentration shows a decrease in rate of photocatalytic bleaching of dye. It may be due to the fact that as the concentration of malachite green was increased, more dye molecules were available for excitation and electron transfer from semiconductor and hence, an increase in the rate was observed. After a certain limit, a decrease in the rate of the reaction was observed with the increase in the concentration of malachite green solution. It may be explained on the basis that an increase in dye concentration beyond a certain limit will not permit the desired light intensity to reach the dye molecules in the bulk of the solution in a limited time domain, or in other words, one can say that dye itself acts as a filter. Hence, decrease in the rate of the reaction has been observed.

\section{Effect of reductant concentration}

Effect of variation of reductant concentration was also studied by taking different concentrations of reductants (Ascorbic acid and EDTA). The results are reported in Figure 4.

It has been observed that the rate of photocatalytic bleaching of dye increases upto $3.33 \times 10^{-5} \mathrm{~mol} \mathrm{~L}^{-1}$ in Set-I (ascorbic acid) and $4.00 \times 10^{-5} \mathrm{~mol} \mathrm{~L}^{-1}$ in Set-II (EDTA) and then decreases with an increase in the concentration of reductant.

This increase may be attributed to the fact that ascorbic acid and EDTA are good hole scavengers and they will prevent the electron-hole recombination process; thus, the dye malachite green can be reduced by electrons present

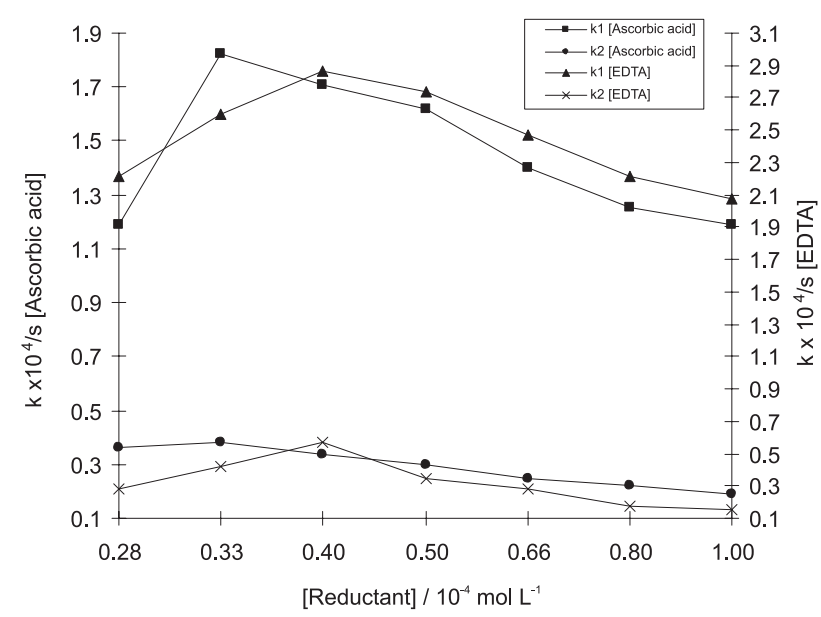

Figure 4. Effect of reductant concentration on photocatalytic reduction of malachite green. Set-I: [Malachite green] $=6.66 \times 10^{-5} \mathrm{~mol} \mathrm{~L}^{-1}, \mathrm{CdS}=$ $0.20 \mathrm{~g}, \mathrm{pH} 8.0$, Light Intensity $=90.0 \mathrm{~mW} \mathrm{~cm}^{-2}$; Set-II: [Malachite green $]=$ $6.66 \times 10^{-5} \mathrm{~mol} \mathrm{~L}^{-1}, \mathrm{CdS}=0.20 \mathrm{~g}, \mathrm{pH} 8.0$, Light Intensity $=80.0 \mathrm{~mW} \mathrm{~cm}{ }^{-2}$.

in the conduction band of the semiconductor CdS. On the other hand, increase in the concentration of reductant beyond $3.33 \times 10^{-5} \mathrm{~mol} \mathrm{~L}^{-1}$ for Set-I and $4.00 \times 10^{-5} \mathrm{~mol} \mathrm{~L}^{-1}$ for Set-II, will hinder the movement of reductant molecules toward semiconductor surface. As a consequence, the electron-hole pair recombination process will be more and limited numbers of electrons are available in the conduction band of $\mathrm{CdS}$ for the reduction of malachite green molecules. This is clearly reflected in the form of a decrease in the rate of photocatalytic bleaching of malachite green.

\section{Effect of amount of semiconductor}

The amount of semiconductor is also likely to affect the process of dye bleaching. Different amounts of photocatalyst were used and the results are reported in Figure 5.

It has been observed that the rate of photobleaching of malachite green first increases upto a certain limit $(0.20 \mathrm{~g})$ and then a slight decrease was observed with an increase in the amount of semiconductor. This may be due to the fact that as the amount of semiconductor was increased, the exposed surface area also increases but after a certain limit, if the amount of semiconductor was further increased, there will be no increase in the exposed surface area of the photocatalyst and a slight decrease in the rate of reaction was observed. It is because any increase in the amount of semiconductor after a certain limit will only increase the thickness of the layer at the bottom of the vessel without affecting the surface area of the photocatalyst. It has also been confirmed on the basis of the geometry of the reaction vessel. The saturation point shifts to a higher value for larger reaction vessels whereas it was shifted to a lower value for reaction vessels of smaller size. 


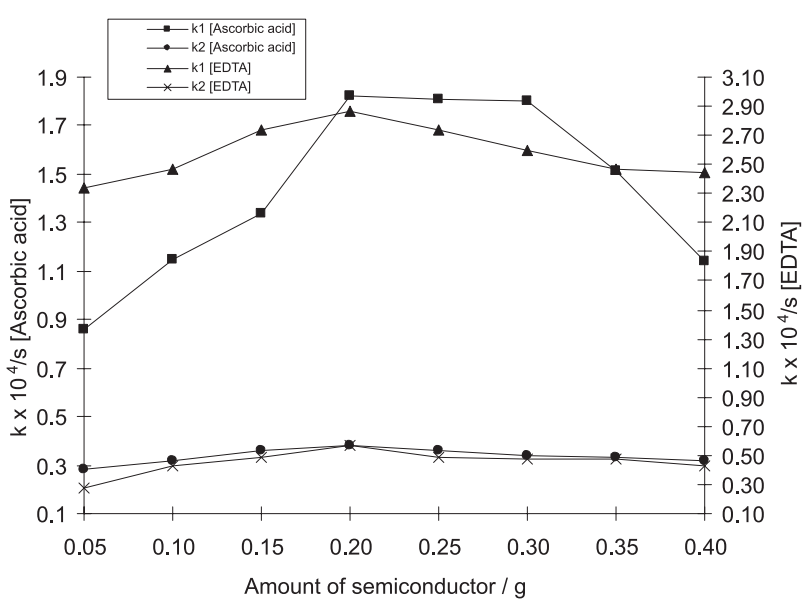

Figure 5. Effect of amount of semiconductor on photocatalytic reduction of malachite green. Set-I: [Malachite green] $=6.66 \times 10^{-5} \mathrm{~mol} \mathrm{~L}^{-1}$, [Ascorbic Acid] $=3.33 \times 10^{-5} \mathrm{~mol} \mathrm{~L}^{-1}, \mathrm{pH} 8.0$, Light Intensity $=$ $90.0 \mathrm{~mW} \mathrm{~m}^{-2}$; Set-II: [Malachite green] $=6.66 \times 10^{-5} \mathrm{~mol} \mathrm{~L}^{-1}$, $[$ EDTA $]=$ $4.00 \times 10^{-5} \mathrm{~mol} \mathrm{~L}^{-1}, \mathrm{pH}$ 8.0. Light Intensity $=80.0 \mathrm{~mW} \mathrm{~cm} \mathrm{c}^{-2}$.

\section{Effect of Light Intensity}

To observe the effect of intensity of light on the photocatalytic bleaching of malachite green, the light intensity was varied. The intensity of light at each distance was measured by Suryamapi (CEL model SM 201). The results obtained are reported in Figure 6.

The data indicate that an increase in the light intensity will increase the rate of reaction and maxima were found at $90.0 \mathrm{~mW} \mathrm{~cm}{ }^{-2}$ and $80.0 \mathrm{~mW} \mathrm{~cm}{ }^{-2}$ for Set-I and Set-II, respectively. It may be explained on the basis that as the light intensity was increased, the number of photons striking per unit area also increased, resulting into a higher rate of degradation. Further increase in the intensity beyond the

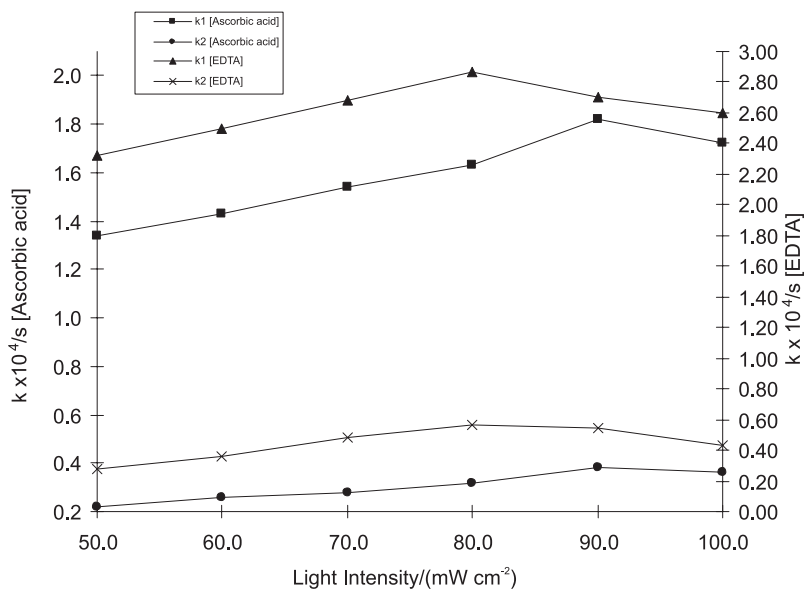

Figure 6. Effect of light intensity on photocatalytic reduction of malachite green. Set-I: [Malachite green] $=6.66 \times 10^{-5} \mathrm{~mol} \mathrm{~L}^{-1}$. [Ascorbic Acid] $=$ $3.33 \times 10^{-5} \mathrm{~mol} \mathrm{~L}^{-1}, \mathrm{CdS}=0.20 \mathrm{~g}, \mathrm{pH} 8.0$; Set-II: [Malachite green] $=$ $6.66 \times 10^{-5} \mathrm{~mol} \mathrm{~L}^{-1},[\mathrm{EDTA}]=4.00 \times 10^{-5} \mathrm{~mol} \mathrm{~L}^{-1}, \mathrm{CdS}=0.20 \mathrm{~g}, \mathrm{pH} 8.0$. maximum limits result in decrease in the rate of reaction. It may be probably due to thermal side reactions.

\section{Mechanism}

On the basis of observed experimental data, a tentative mechanism for the photoreduction of malachite green has been proposed:

$$
\begin{aligned}
& \mathrm{CdS} \stackrel{\mathrm{hv}}{\longrightarrow} \mathrm{h}^{+}+\mathrm{e}^{-} \\
& \mathrm{h}^{+}+\mathrm{e}^{-} \stackrel{\mathrm{hv}}{\longrightarrow} \text { Heat } \\
& \mathrm{D}^{+}+\mathrm{H}^{+}+2 \mathrm{e}^{-} \stackrel{\mathrm{k}_{1}}{\longrightarrow} \mathrm{DH}^{-} \text {(leuco form) } \\
& \mathrm{R}^{+} \mathrm{h}^{+} \stackrel{\mathrm{k}_{2} \longrightarrow \mathrm{R}^{+}}{\longrightarrow} \text { Products } \\
& \mathrm{DH}^{-} \text {(leuco) } \longrightarrow \text { Prouct }
\end{aligned}
$$

The semiconductor CdS absorbs radiations of energy corresponding to its band gap and generates electron-hole pair. The electrons and holes will remain in conduction and valence band of the semiconductor, respectively. The electron and hole may recombine to release the energy absorbed in the form of heat radiations. The cationic dye malachite green $\left(\mathrm{D}^{+}\right)$combines with two electrons and a proton to give its reduced form $\left(\mathrm{DH}^{-}\right)$. This step is the rate determining step for the photocatalytic bleaching of malachite green. The leuco form of the dye ultimately degrades to final products.

The reductant $\mathrm{R}$ (ascorbic acid or EDTA) plays an important role in the photobleaching of malachite green as a sacrificial electron donor. The reductant reacts with the photogenerated holes and thus reduces the rate of electronhole recombination. The use of ascorbic acid and EDTA as good hole scavengers in larger concentration prevents the dye molecules from undergoing degradation by injecting electron into the conduction band of the semiconductor CdS. However, photooxidation of malachite green would also be possible as reported by Ollis et al. ${ }^{14-16}$

This possibility of photooxidation is checked by the presence of reductants. The photocorrosion of the semiconductor CdS by holes may also compete with the utilization of holes by reductant molecules. But the presence of reductant will get an edge over these two reactions. Hence, the use of reductant not only prevents the photooxidation of dye malachite green but also the semiconductor CdS from photocorrosion.

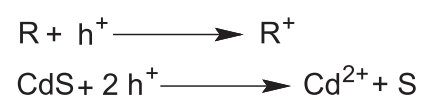

This fact was confirmed by carrying out this reaction in absence of reductants where pale yellow colloidal particles of sulfur were observed. 


\section{Conclusions}

Thus, the malachite green dye can be degraded photocatalytically by $\mathrm{CdS}$ in the presence of sacrificial electron donors like ascorbic acid or EDTA avoiding photocorrosion of CdS.

\section{Acknowledgments}

We are thankful to Prof. Suresh C. Ameta for valuable discussions and suggestions.

\section{References}

1. Ameta, S. C.; Chaudhary, R.; Ameta, R.; Vardia, J.; J. Ind. Chem. Soc. 2003, 80, 257.

2. Scheavello, M.; Heterogeneous Catalysis, Wiley: New York, 1997.

3. Takazawa, T.; Watarable, T.; Honda, K.; J. Phys. Chem. 1978, $82,1391$.

4. Zang, L.; Shen, J.; J. Chem. Soc., Chem. Commun. 1996, 472.

5. Kominami, H.; Kumamoto, H.; Kera, Y.; Ohtani, B.; J. Photochem. Photobiol. 2003, 160 A, 99.

6. Ameta, R.; Vardia, J.; Punjabi, P. B.; Ameta, S. C.; Indian J. Chem. Technol. 2006, 13, 114.
7. Chen, Y. X.; Wang, K.; Liping, L.; J. Photochem. Photobiol. 2004, 163A, 281.

8. Ozkan, A.; Ozkan, M. H.; Gurkan, R.; Akay, M.; Sokmen, M. J.; J. Photochem. Photobiol. 2004, 163A, 29.

9. Rao, P.; Patel, G.; Sharma, S. L.; Ameta, S. C.; Toxicol. Environ. Chem. 1997, 60, 155.

10. Sharma, A.; Rao, P.; Mathur, R. P.; Ameta, S. C.; J. Photochem. Photobiol. 1995, 86A, 197.

11. Sharma, A.; Ameta, R.; Mathur, R. P.; Ameta, S. C.; Hung, J. Indus. Chem. 1995, 23, 31.

12. Marchesi, E.; Rota, C.; Fann, Y. C.; Chignell, C. F.; Mason, R. P.; Free Radic. Biol. Med. 1999, 26, 148.

13. Punjabi, P. B.; Ameta, R.; Vyas, R.; Kothari, S.; Ind. J. Chem. 2005, 44A, 2266.

14. Ollis, D. F.; Environ. Sci. Technol. 1985, 19, 480.

15. Ollis, D. F.; Pellizzetti, E.; Serpone, N.; Environ. Sci. Technol. 1991, 25, 1523.

16. Ollis, D. F.; Pellizzetti, E.; Serpone, N.; Photocatalysis Fundamentals and Applications, Wiley-Interscience: New York, 1989, p. 603.

Received: September 20, 2008 Web Release Date: October 16, 2009 